\title{
CONTROLE POPULACIONAL DE ESPÉCIES SILVESTRES INVASORAS POR MEIO DE LAQUEADURA E VASECTOMIA EM PRIMATAS Callithrix penicillata: RELATO DE CASO
}

\author{
Davi Fragôso da Silva ${ }^{1}$ \\ Elisângela Barboza da Silva ${ }^{2}$ \\ André Preturlon Terra ${ }^{3}$
}

\begin{abstract}
RESUMO
Saguis-de-tufo-preto (Callithrix penicillata) são consideradas espécies invasoras em regiões do sul e sudeste do Brasil. Espécies invasoras interferem com a dinâmica do ecossistema em áreas as quais foram introduzidas. A hibridização, a competição e a predação de outros animais são alguns dos problemas causados por estes calitriquídeos. A esterilização de primatas que se encontram em Centros de Recuperação para Animais Silvestres é um procedimento necessário que visa o controle populacional da espécie quando são destinadas para soltura. Técnicas como a de laqueadura e vasectomia, que preservam as glândulas sexuais que são imprescindíveis nestes primatas, pois necessitam de sua produção hormonal para se estabelecer e viver em grupos na natureza. Sendo assim, objetivou-se descrever a técnica cirúrgica de esterilização de um macho e uma fêmea da espécie C. penicillata.
\end{abstract}

Palavras-chave: cirurgia veterinária, controle populacional, espécies invasoras, sagui-detufo-preto.

\section{POPULATION CONTROL OF INVASIVE WILD SPECIES THROUGH TUBAL LIGATION AND VASECTOMY IN PRIMATES CALLITHRIX PENICILLATA: CASE REPORT}

\begin{abstract}
Black-tufted marmosets (Callitrhix penicillata) are considered invasive species in the regions of Southern and Southeast of Brazil. Invasive species interfere with the dynamics of ecosystem in areas which they were introduced. The hybridization, the competition and the predation of other animals are some of the problems caused by callitrichids. The sterilization of primates that are in wildlife rehabilitation centers is a necessary procedure because it is intended to control the population growth from species destined to reintroduction into the wild. Technics like tubal ligation and vasectomy that maintain the sexual glands are essential to these primates since they need their hormones production to be able to live in groups in the wild. Therefore the aim of this work is to describe in details the sterilization technique of a male and a female of $C$. penicillata.
\end{abstract}

Keywords: Black-tufted marmoset, invasive species, populacional control, veterinary surgery.

\footnotetext{
${ }^{1}$ Bacharel em Medicina veterinária, Universidade Estadual de Santa Cruz. Correspondência.

${ }^{2}$ Professora Doutora, Departamento de Ciências Agrárias e Ambientais, Universidade estadual de Santa Cruz - UESC.

${ }^{3}$ Médico Veterinário, Ortopedista e Cirurgia Veterinária
} 


\title{
CONTROL DE LA POBLACIÓN DE ESPECIES SILVESTRES INVASORAS MEDIANTE LIGADURA DE TROMPAS Y VASECTOMÍA EN PRIMATAS CALLITHRIX PENICILLATA: INFORME DEL CASO
}

\begin{abstract}
RESUMEN
Los titíes de Pincel Negro (Callithrix penicillata) son considerados especies invasoras en las regiones del sur y el surdste de Brasil. Las especies invasoras interfieren con la dinámica de los ecosistemas en las áreas em las que fueron introducidas. La hibridación, la competencia y la depredación de otros animales son algunos de los problemas causados por estos callitrícidos. La esterilización de los primatas que se encuentran en Centros de Recuperación de Animales Silvestres es un procedimiento necessário dedicado a controlar la población de la especie destinada a su liberación. Técnicas como la ligadura de trompas y la vasectomía, las cuales preservan las glándulas sexuales, son imprescindibles para estos primatas ya que necesitan su producción hormonal para establecerse y vivir en grupos en la naturaleza. Por tanto, este estudio tiene como objetivo describir la técnica quirúrgica de esterilización de un macho y una hembra de la especie C. penicillata.
\end{abstract}

Palabras claves: cirugía veterinaria, control de población, especies invasoras, tití de pincel negro.

\section{INTRODUÇÃO}

As espécies de primatas mais conhecidas do gênero Callithrix costumam viver em grupos familiares. A espécie Callithrix penicillata é endêmica do nordeste e centro-oeste predominante em áreas da caatinga, cerrado e mata atlântica. Reproduzem-se durante todo o ano e possuem uma dieta rica e bem variada consumindo desde exsudatos, sementes, flores, frutos, néctar, além de artrópodes, moluscos, filhotes de aves e mamíferos, anfíbios e pequenos lagartos (1).

Segundo o Ministério do Meio Ambiente (2) as espécies C. penicillata e C. jacchus são consideradas invasoras em diversas regiões do Brasil, dando destaque para regiões do sul e sudeste. Espécies invasoras estatisticamente são causadoras da segunda maior perda de biodiversidade no planeta. Ao serem introduzidas em um novo ambiente, muitas dessas espécies não sobrevivem devido as diferentes condições do seu novo habitat, porém, aquelas que conseguem se adaptar possuem grandes chances de se estabelecer causando um potencial perigo de extinção às espécies nativas (3).

Segundo Vale e Prezoto (4) o processo de invasão de animais em novos ambientes é dividido em etapas. A primeira fase é caracterizada pelo período de introdução da espécie no novo habitat. A fase de colonização acontece em seguida, após as superações das barreiras encontradas pela espécie invasora. Caso sobreviva, segue-se pela fase de naturalização onde a nova espécie efetiva sua reprodução conseguindo dispersar seus genes e por fim a fase de impacto onde os danos, sejam ecológicos ou econômicos, ocorrem. Estes processos podem ocorrer tanto de maneira linear como simultânea.

De acordo com Levacov et al. (5), os primatas C. jacchus, Cebus apella, C. penicillata e Callithrix geoffroyi são alvos do tráfico interestadual e mais frequente em Centros de Recuperação e Triagem de Animais Silvestres. Sendo os animais retirados de biomas das regiões do norte, nordeste e centro-oeste. Demonstrando assim uma grande quantidade de espécies exóticas e potencialmente invasoras trazidas para região sul e sudeste.

Devido a grande flexibilidade adaptativa das espécies $C$. penicillata e que ao serem introduzidos em áreas não endêmicas onde não possuem predadores e/ou parasitos no ecossistema, geralmente se tornam consumidores do topo da cadeia (6). Aumentado os problemas causados devido ao aumento exacerbado da população.

Silva DF, Silva EB, Terra AP. Controle populacional de espécies silvestres invasoras por meio de laqueadura e vasectomia em primatas Callithrix penicillata: Relato de caso. Vet. e Zootec. 2018 mar.; 25(1): 099-105. 
Mais um problema gerado pelas invasões, é o do declínio da fauna ornitóloga devido à predação de ninhos por Callithrix spp. Além das aves, mamíferos também são ameaçados pela invasão biológica por calitriquídeos. Como o sagui-da-serra-escuro ( $C$. aurita) e o saguida-serra ( $C$. flaviceps) devido a sua capacidade de reprodução e hibridização com estas espécies que, por conseguinte, causa o seu desaparecimento devido à perda genética (7).

Outra espécie que corre riscos com a invasão de $C$. penicillata é o mico-leão-dourado (Leontophitecus rosalia) a qual já se encontra ameaçada devido a grande perda de seu habitat, remanescendo em fragmentos da mata atlântica. Além disso, estudos demonstraram que $C$. penicillata invasores, possuem maior capacidade de adaptação em áreas degradadas em comparação com espécies do gênero L. rosalia prejudicando ainda mais as condições de conservação do mico-leão-dourado (4).

\section{RELATO DE CASO}

Um sagui macho e uma fêmea da espécie $C$. penicillata, foram escolhidos aleatoriamente dentre os 27 exemplares de Callithrix spp. presentes em um centro de recuperação de animais silvestres. Os animais hígidos foram então conduzidos para o centro cirúrgico objetivando-se executar o procedimento de esterilização para a posterior soltura destes animais.

Os primatas foram levados em caixas de transporte onde ficaram em jejum hídrico e alimentar por três horas até o momento do procedimento cirúrgico. Por serem animais com alta velocidade metabólica foi administrado $0,2-0,5 \mathrm{ml}$ de glicose $50 \%$ via oral antes da indução anestésica evitando uma queda acentuada de glicose no organismo e o aparecimento de sintomas de hipoglicemia, sendo frequente, os animais apresentarem convulsões.

A indução anestésica foi realizada cobrindo-se a caixa de transporte com material plástico e bloqueando todas as saídas de ar ficando apenas uma abertura para entrada da mangueira pela qual o anestésico volátil era infiltrado, sendo utilizado o isoflurano a $5 \%$. $\mathrm{O}$ animal então era observado até o momento de decúbito, e o tempo médio variou de 5-10 min.

O primeiro animal uma fêmea, adulta, pesava $0,334 \mathrm{~kg}$ que após a indução anestésica foi mantida com o agente inalatório isoflurano em sistema aberto do tipo Baraka, com utilização de máscara não sendo necessário sua intubação. Durante o trans-cirúrgico, as concentrações do isoflurano variaram de $0,2-1,0 \%$.

O animal foi posicionado na mesa em decúbito dorsal para realização da tricotomia, antisepsia habituais. Logo então, uma pequena incisão mediana retroabdominal de aproximadamente $3 \mathrm{~cm}$ foi feita objetivando-se acessar a cavidade e o sistema reprodutor feminino. Foram expostos e identificados o útero, os cornos uterinos como também os ovários, para então, dar início ao procedimento de dupla ligadura na região dos ístimos tubários (Figura 1).

Estes foram duplamente pinçados em ambos os lados, direito e esquerdo, deixando uma pequena região da tuba uterina entre as duas pinças onde, aproximadamente $1 \mathrm{~cm}$ foi excisado. Em seguida fez-se a ligadura da porção cranial e caudal das tubas. A ligadura foi feita com fio de nylon 3-0 em ambos os lados. O procedimento foi repetido na tuba uterina contralateral.

Não havendo sangramentos durante o procedimento, os orgãos foram reposicionados na cavidade para prosseguir com a síntese. Foi utilizado o fio poliglactina 910 3-0 para a sutura da musculatura e subctâneo utlizando os padrões simples contínuo e zig-zag, respectivamente e para a síntese da pele foi utilizado cola cirúrgica a base de 2-octil-cianoacrilato. 


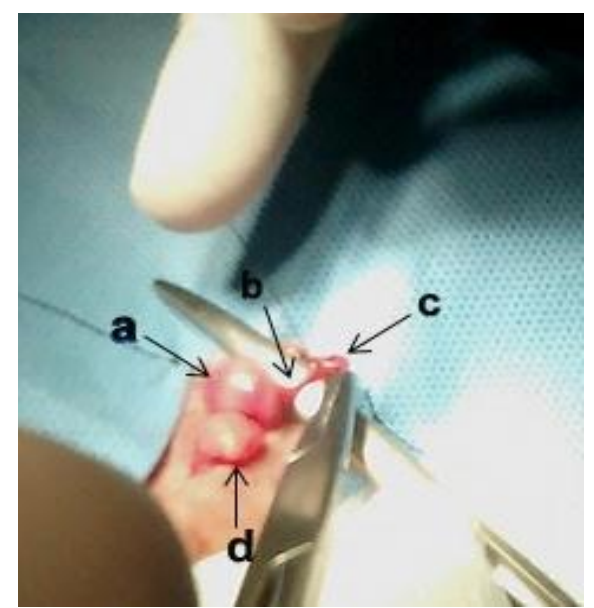

Figura 1. Posicionamento anatômico dos órgãos do sistema reprodutor feminino (a) útero (b) corno uterino esquerdo direito (c) ovário esquerdo. (d) bexiga

Terminada a cirurgia da fêmea, o macho, também do gênero $C$. penicillata com $0,304 \mathrm{~kg}$, foi conduzido para o procedimento de vasectomia. Seu preparo, indução e manutenção foi realizado da mesma maneira que a fêmea.

Uma incisão mediana ventral foi feita acima da sínfise púbica pretendendo-se alcançar o funículo espermático e seus ductos e em seguida foi feita a localização destas estruturas (Figura 2), divulsionou-se os ductos deferentes da fáscia espermática como também da veia e artéria presentes no funículo espermático para então pinçá-los. Foram pinçandas duas porções do ducto, cranialmente e caudalmente deixando um pequeno espaço entre as pinças que foi excisado (Figura 3), em seguida realizou-se a ligadura das duas extremidades.

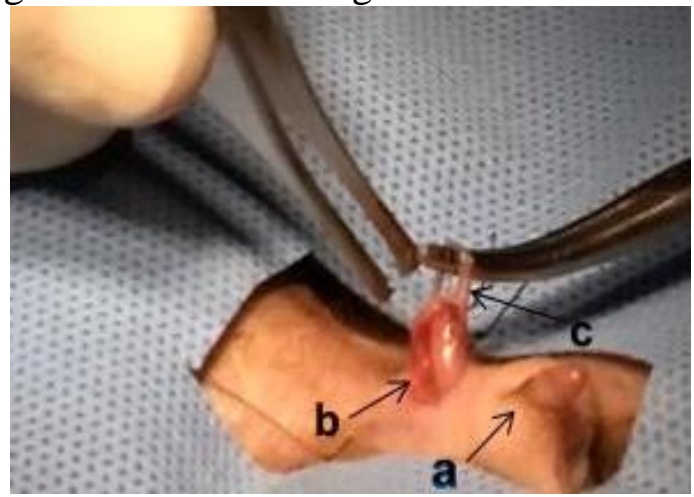

Figura 2. Exposição do ducto deferente para realização da vasectomia. (a) pênis (b) funículo espermático direito (c) ducto deferente.

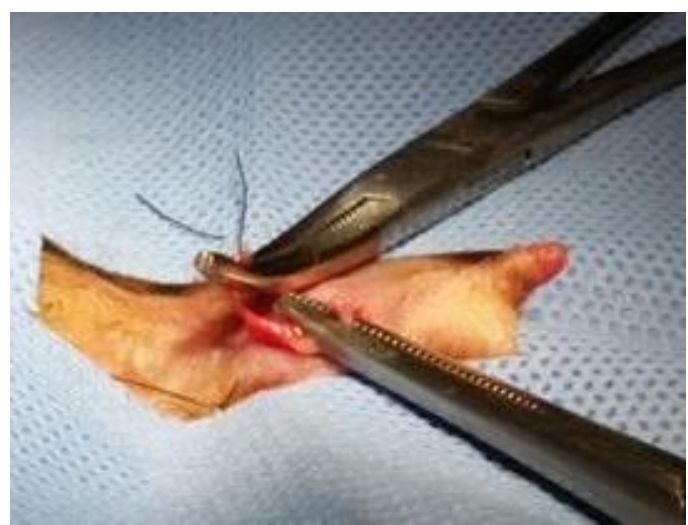

Figura 3. Ducto deferente seccionado aguardando a ligadura das porções cranial caudal. 
Utilizou-se o fio nylon 3-0 para ligadura dos ductos. O procedimento foi relaizado no ducto deferente direito e esquerdo.Após o reposicionamento das estruturas em seu local de origem, a síntese da pele foi feita com cola cirúrgica.

Durante o transcirúrgico os animais apresentaram-se estáveis com padrões fisiológicos normais para a espécie, frequência respiratória $20-40 \mathrm{rpm}$ e temperatura entre $38-39,0{ }^{\circ} \mathrm{C}$. Devido a alta frequência cardíaca da espécie, foi analisado com o estetoscópio apenas a regularidade dos batimentos, sendo os valores de referência para a espécie de: $38-39,7{ }^{\circ} \mathrm{C}$, $20-50 \mathrm{rpm}$ e $240-350 \mathrm{bpm}$.

Logo ao término da cirurgia foram adminstrados pela via intramuscular cloridrato de tramadol $3 \mathrm{mg} / \mathrm{kg}$ e penicilina $20.000 \mathrm{UI} / \mathrm{kg}$ para prolongamento da analgesia e profilaxia antibiótica, respectivamente em ambos os animais.

No pós-cirúgico os animais ficaram em observação no centro de recuperação onde eram alimentados e medicados. Foi prescrito para os saguis a administração de enrofloxacina $5 \mathrm{mg} / \mathrm{kg}$ e dipirona $10 \mathrm{mg} / \mathrm{kg}$ via oral, uma vez ao dia durante 7 dias. Para receber a medicação, os animais eram retirados do recinto com luvas de raspa evitando-se possíveis mordidas.

\section{DISCUSSÃO E CONCLUSÕES}

$\mathrm{O}$ procedimento de vasectomia em machos e laqueadura em fêmeas é recomendando para animais silvestres que são destinados para o retorno a natureza. A esterilização de calitriquídeos diminui a ocorrência de efeitos negativos comparados à castração, visto que esses animais convivem em grupos e a produção hormonal pela glândulas sexuais interfere enormemente no comportamento social e sexual dos indivíduos (8).

Primatas de pequeno porte como os da espécie Callithrix, necessitam realizar jejum alimentar em reduzido período de tempo comparado com outras espécies, devido a sua alta taxa metabólica. É recomendando o jejum de 6-8 horas antes da cirurgia. Entretanto, não existe ainda estabelecido um intervalo ideal para espécie Callithrix penicillata (9).

Durante o procedimento de esterilização optou-se pela indução com anestesia inalatória com isoflurano, agente comumente usado em pequenos primatas, pois são facilmente induzidos com anestesia volátil, seja usando máscaras ou caixas para indução. Os animais foram induzidos em suas próprias caixas de transporte devido à praticidade, além de evitar a manipulação dos saguis e consequente estresse e fuga pelo local. Este método teve funcionalidade semelhante à utilização de caixas para indução anestésica em pequenos animais $(9,10)$.

A manutenção anestésica foi realizada com o isoflurano devido aos baixos riscos de mortalidade e morbidade nestes primatas, além de possuir uma baixa CAM de 1,2\% (9). Os animais não foram intubados, porém em cirurgias de longa duração, esse procedimento é aconselhado visando à proteção das vias aéreas e correto fornecimento de oxigênio. A intubação endotraqueal de primatas com peso menor que $500 \mathrm{~g}$ pode se tornar de difícil realização, podendo ser necessária à adaptação de sondas utilizando-se como, por exemplo, cateteres ou sondas uretrais (10).

Os procedimentos de esterilização foram baseados em técnicas cirúrgicas realizadas em humanos devido à semelhança anatômica entre as espécies. Na laqueadura foi utilizada a técnica de Parkland de salpingectomia parcial bilateral a qual é frequentemente usada na medicina humana (11).

A mesma técnica de dupla ligadura foi utilizada para a vasectomia dos machos a qual também se assemelha com a humana (12). Esta técnica já foi realizada com sucesso e descrita em um sagui da espécie Callithrix jacchus por Morris e David (13).

Animais do gênero Callithrix assim como outros primatas são conhecidos pela sua grande curiosidade (14). Conhecendo estas características comportamentais da espécie, optouse pela utilização de cola cirúrgica para sutura da pele ao invés da tradicional síntese com fio

Silva DF, Silva EB, Terra AP. Controle populacional de espécies silvestres invasoras por meio de laqueadura e vasectomia em primatas Callithrix penicillata: Relato de caso. Vet. e Zootec. 2018 mar.; 25(1): 099-105. 
de nylon, pois os fios de sutura poderiam estimular os saguis a removerem os pontos causando novas lesões prejudicando o pós-operatório.

No pós-cirúrgico os animais foram medicados com dipirona sódica via oral e enrofloxacina via oral, uma vez ao dia pretendendo-se promover uma analgesia e profilaxia de infecções bacterianas respectivamente. Estes medicamentos foram adotados devido ao seu amplo uso e baixos efeitos adversos em animais silvestres e exóticos sendo inclusive recomendado para primatas da espécie $C$. penicillata (15).

Conclui-se então que a laqueadura e vasectomia de primatas Callithrix penicillata é um procedimento simples com baixos riscos aos animais e que deve ser realizado devido a sua função no controle populacional destas espécies, amenizando os impactos causados no ecossistema advindo dos processos de invasões e proliferação permitindo o seu retorno à natureza. A descrição da técnica cirúrgica nestes primatas também colabora fornecendo informações sobre a clínica e cirurgia de animais silvestres da fauna brasileira área em constante desenvolvimento e que sempre necessita de novos dados.

\section{REFERÊNCIAS}

1. Verona CED, Pissinatti A. Primates - Primatas do novo mundo (sagui, macaco-prego, macaco-aranha, bugio e muriqui). In: Cubas ZS, Silva JCR. Catão-Dias JL. Tratado de animais selvagens. 2a ed. São Paulo: Rocca; 2014. p.723-30.

2. Ministério do Meio Ambiente (BR). Estratégia nacional sobre espécies exóticas invasoras. Brasília: Ministério do Meio Ambiente; 2009.

3. Dechoum MS, Pessato RD. Invasões biológicas: uma ameaça invisível. Recife: AMANE (Associação para Proteção da Mata Atlântica do Nordeste); 2010.

4. Vale CA, Prezoto F. Invasões biológicas: o caso do mico estrela Callithrix penicillata. CES Rev. 2015;29:58-76.

5. Levacov D, Jerusalinky L, Fialho MS. Levantamento dos primatas recebidos em centros de triagem e sua relação com o tráfico de animais silvestres no Brasil. In: Anais do 120 Congresso Brasileiro de Primatologia; 2011; Belo Horizonte. Belo Horizonte: SBP; 2011.

6. Traad RM, Leite JCM, Weckerlin P, Trindade S. Introdução das espécies exótica Callithrix penicillata (Geoffroy, 1812) e Callithrix jacchus (Linnaeus, 1758) em ambientes urbanos (Primates Callithrichidae). Rev Meio Ambiente Sustentabilidade. 2012;2:9-23.

7. Begott RA, Landesmann LF. Predação de ninhos por um grupo híbrido de Saguis (Callithrix jacchus/penicillata) introduzidos em área urbana: implicações para a estrutura da comunidade. Neotrop Primates. 2008;15:28-9.

8. European Association of Zoos and Aquaria. Husbandry guidelines for Callitrhichidae. 2a ed. Saint-Aignan: Beauval Zoo; 2010.

9. Ølberg RA. Monkeys and gibbons In: West G, Heard D, Caulkett N. Zoo animal and wildlife - immobilization and anestesia. Phoenix: Blackwell; 2007. p.375-84.

10. Longley LA. Anaesthesia of exotic pets. 1a ed. St. Louis: Saunders; 2008. p.103-10. 
11. Campagnolo IM. Avaliação da cauterização completa da luz tubária com diferentes potências de eletrocoagulação bipolar para esterilização feminina [dissertação]. Porto Alegre: Faculdade de Medicina, Universidade Federal do Rio Grande do Sul; 2012.

12. Netto NR, Neves PA. Tratado de ginecologia. 2a ed. São Paulo: Rocca; 2000. v.1, p.7437.

13. Morris TH, David CL. Illustrated guide to surgical technique for vasectomy of common marmoset. Lab Anim. 1993;27:381-4.

14. Milagres AP. Caracterização dos sítios de dormida de saguis híbridos Callithrix sp. (Mammallia, Primates), em um fragmento florestal urbano [dissertação]. Viçosa: Universidade Federal de Viçosa; 2015.

15. Valverde CR. Primates. In: Carpenter JW. Exotic animal formulary. 3a ed. St. Louis: Saunders; 2005. p.495-527.

Recebido em:

Aceito em: 